\title{
APUNTES PARA LA DEMOGRAFÍA DE LA ALJAMA JUDÍA DE SAGUNTO EN LOS SIGLOS BAJOMEDIEVALES
}

\author{
JOSÉ HINOJOSA MONTALVO
}

Universidad de Alicante

Si difícil resulta establecer la demografía de los grupos cristianos en la época bajomedieval en el reino de Valencia ', el empeño es mucho mayor cuando intentamos abordar las comunidades judías, de las que no existe ningún estudio demográfico específico en nuestro marco geográfico, aunque sí algunas noticias dispersas en las monografias sobre las distintas aljamas ${ }^{2}$. La demografia no formaba parte de las inquietudes del hombre medieval, y si en algún momento interesó saber cuántos eran, lo fue por razones fiscales. Gracias a ello podemos intentar una aproximación a la población judía de la medieval Morvedre, actual Sagunto, a partir de dos listas conservadas del impuesto del morabatí recaudado en 1379 y 1445, en las que figuran los nombres de los cabezas de familia. Somos conscientes de la parquedad de datos y de la imposibilidad de trazar unas líneas

${ }^{1}$ Entre la bibliografia sobre demografia medieval valenciana podemos citar: $F$. ARROYo ILERA, "Estructura demográfica de Segorbe y su comarca en el siglo XV", Hispania 29 (1969) 287-313; R. Ferrer Navarro, "La Plana: Estructura demográfica en el siglo XV", Cuadernos de Historia. Anejos de la revista Hispania 5 (1975) 67-82; E. Guinor, "Demografia medieval del nord del País Valencià", en Estudis sobre la Població del Pais Valencià, Valencia 1988, págs. 229-250; J. Hinojosa Montalvo, "Demografia y poblamiento en Alicante durante la Baja Edad Media: siglos XIIIXV", en Estudios de Historia Medieval. Homenaje a Luis Suárez, Valladolid 1991. págs. 267-282; pág. Pérez Puchal, Geografla de la població valenciana, Valencia 1976; A. RuBio Vela, "Sobre la población de Valencia en el cuatrocientos", Boletín de la Sociedad Castellonense de Cultura LVI (1980) 158-170; A. SANTAMARÍA ArándeZ, "La demografia en el contexto de Valencia. Siglo XV", Medievalia 10 (1992) 363-386.

2 J. Doñate Sebastiá - J. R. Magdalena Nom de Deu, Three Jewish Communities in Medieval Valencia: Burriana, Castellón de la Plana, Villarreal, Jerusalem 1990; J. Hinojosa Montalvo, "La comunidad hebrea en Valencia: del esplendor a la nada (1377-1391)", Saitabi 31 (1981) 42-72; J. Hinojosa Montalvo, The Jews of the Kingdom of Valencia from Persecution to Expulsion, 1391-1492, Jerusalem 1993. 
siquiera generales, pero estos datos son los únicos conocidos por el momento sobre judíos valencianos, lo cual incrementa su valor para el historiador ${ }^{3}$.

Recordemos que el impuesto del morabatí se estableció en el reino de Valencia en 1266 y se mantuvo hasta comienzos del siglo XVIII, en que desaparecieron las instituciones forales privativas del reino. Equivalía al monedaje de otros reinos y lo abonaban cada septenio todas aquellas personas que tuvieran una base imponible mínima de 105 sueldos. De los cuatro cuadernos del morabatí de Sagunto que se han conservado $(1379,1421,1431$ y 1445) sólo en dos de ellos (1379 y 1445) aparecen las listas nominales de parte de los judíos de la localidad, a los que habría que añadir el morabatí de 1421. Datos parcos, escuetos, pero que son los únicos que nos permiten aproximarnos a la población hebrea de Sagunto.

Desde una perspectiva global de lo que debió de ser la demografía judía en el reino de Valencia no debemos olvidar que en el mismo no hubo muchos judíos, y su número no resiste comparaciones con otros reinos vecinos como Castilla o Aragón. Tampoco en el terreno concreto de las cifras - que son muy escasas y difusas, tanto para cristianos como para judíos- los hebreos representaban un porcentaje destacado de población en el conjunto del reino y sólo en poblaciones como Valencia, Sagunto o Játiva se puede hablar de una presencia judía más o menos notable. De hecho, cuando en 1492 se produjo la expulsión y la marcha hacia el exilio sólo había en el reino de Valencia poco más de un millar de judíos, de los cuales la mayoría eran de Sagunto.

Sagunto, la medieval Morvedre, poseía una floreciente comunidad hebrea que tiene su punto de arranque en los siglos bajomedievales, en los años que siguen a la conquista cristiana, pero cuyas bases, como en otras localidades, podrían datarse en la etapa de dominio islámico, de la que carecemos de datos. En cualquier caso, la segunda mitad del siglo XIII y primera del XIV fueron los años de crecimiento y esplendor de la aljama. Jaime I asignó a los hebreos que acudieran a instalarse en la villa casas, huertos, viñas y alquerías,

${ }^{3}$ Quiero expresar mi más profundo agradecimiento a Jesús Villalmanzo, técnico archivero del Archivo del Reino de Valencia, que me puso en conocimiento de las citadas listas y me facilitó la correspondiente documentación, la cual forma parte de un trabajo elaborado con J. Aleixandre "La población de Morvedre durante los siglos XIV y XV a través de los morabatines de 1379 y 1445». En prensa. 
dándoles un espacio urbano para la judería: el que luego fue barrio de la Sangre Vieja y Nueva y les Penyetes.

Ya desde el momento de su fundación la judería saguntina estuvo llamada a un próspero futuro, y su influencia se ejerció sobre lugares próximos como Benavites, Burriana, Canet, Marines, etc. Durante los reinados de Jaime I y Pedro III estuvieron al frente de la bailía local judíos como Salamó de la Cavallería (1273), Jucef Abençaprut (1277-1280) o Salamó Constantó (1288).

Los privilegios de la Corona contribuyeron al desarrollo de la aljama y a regular las relaciones con sus vecinos cristianos, tratando de evitar tensiones y desavenencias, particularmente virulentas durante la Semana Santa. Jaime II les autorizó a rodear la judería con un muro en 1321, mientras que en 1328 Alfonso IV les permitió que construyeran un nuevo cementerio debajo del castillo, en un lugar donde no se perjudicaran los intereses de la Corona ni de los vecinos.

Pero a mediados de la centuria la crisis se dejó sentir sobre la aljama de Sagunto, igual que en el resto de la localidad. No sólo fue la crisis demográfica causada por la peste negra de 1348, imposible de cuantificar en cifras, sino lo que posiblemente fue más grave: las guerras, que hicieron de los judíos una de las víctimas propiciatorias. En efecto, en 1348 la judería de Sagunto fue asaltada y saqueada por las tropas unionistas de Valencia, enfrentadas a Pedro el Ceremonioso. Murieron seis hombres y cinco mujeres, además de perderse cuantiosos bienes, lo que puso a muchos judíos en una dificil situación económica, a los que el monarca trató de compensar mediante indemnizaciones económicas.

Mucho más grave fue la guerra con Castilla, la de los dos Pedros (1361-1365), que dejó graves secuelas entre los hebreos de la villa, cuando ésta fue ocupada por las tropas castellanas de Pedro I. Los judíos fueron expulsados y se refugiaron en Valencia, donde sufrieron toda clase de atropellos, teniendo que interceder Pedro el Ceremonioso, que envió a Pere Colom, procurador de los lugares que la reina Leonor tenía en el reino de Valencia, con la orden de que los judíos saguntinos salieran cuatro días después del día de Pascua con destino a Tortosa o Lérida, a fin de no ser apedreados ${ }^{4}$. Vemos una vez más al judío como víctima de las tensiones sociales 335 .

${ }^{4}$ A. Chabret, Sagunto. Su historia y sus monumentos, Barcelona 1888, II, pág. 
internas de la sociedad cristiana o de unas guerras, en las que se limitaron a ser sujetos pacientes.

El resultado debió de ser la desorganización temporal de la aljama de Sagunto, que quedaría empobrecida tras estos tremendos embates foráneos. Así lo reconoce la reina Leonor, de cuyo patrimonio Sagunto formaba parte, cuando el 13 de julio de 1366, para compensar a los judíos de los daños sufridos durante la ocupación castellana, les concede que, desde que la villa fue incorporada a la corona real de nuevo, del el 1 de septiembre pasado al 31 de agosto presente, no abonen ningún tributo, pecha, cena u otra exacción, ni siquiera los 500 sueldos que en los próximos dos años, a partir del 1 de septiembre, debían darle como cena, pecha, questia, etc. 5.

La documentación de estos años habla de "fretura e inopia" de la aljama de Sagunto y el 12 de agosto de 1366, ante la noticia de que algunos judíos saguntinos, que habían perdido sus casas, iban por la villa y el término vagando y mendigando por otras aljamas, la reina Leonor ordena a Bonafonat de Sant Feliu, baile de Sagunto, que efectue un pregón dando un plazo de tiempo (que deja a su arbitrio) para que todos estos judíos regresen a Sagunto y vuelvan a tener aquí sus domicilios y a pagar sus pechas, so pena de confiscación de bienes y derechos ${ }^{6}$. Era una medida similar a la que se dió por entonces para la aljama de Liria, también del patrimonio de la reina, y cuyo objetivo fundamental era mantener el nivel de ingresos de la renta feudal de la soberana, ya que el tributo comunitario que debía entregarle la aljama se veía disminuida con la marcha de estos judíos en difícil situación económica.

Es en este difícil contexto de salida de una fuerte crisis, ocasionada por la guerra de Castilla y la lenta recuperación posterior, donde hay que colocar la recaudación del morabatí de Sagunto de 1379. De acuerdo con los censos conservados, la población cristiana de Sagunto había sufrido en 1361 un descenso desde mediados de siglo (de 1.435 fuegos en 1355 a 1.402 en 1361), que se acentuó en 1373 a causa de la guerra de los dos Pedros, quedando con tan sólo 892 fuegos (3.568 habitantes). La paz trajo consigo la recuperación demográfica de la villa, visible en el censo cristiano, que pasó a

5 ACA., Real Cancillería. Reg. 1574, fol. 111v-112r.

6 ACA., Real Cancillería. Reg. 1574, fol. 116v-117r. 
1.297 fuegos, es decir 5.188 habitantes, aplicando un coeficiente 4 por foc.

En este año de 1379, primer censo del morabatí que conserva datos judíos, los fuegos censados en la aljama son 43, es decir 172 habitantes, que en el conjunto de la población saguntina representan el $3,3 \%$. Ante la falta de datos anteriores no podemos establecer posibles variaciones con años anteriores, aunque cabe suponer un descenso con relación a la población que pudiera haber en la judería a mediados de la centuria, a tenor de las dificultades por las que atravesó Sagunto.

Estos 43 fuegos judíos recogen el nombre de los cabezas de familia, varones en su mayoría o el de las mujeres que desempeñaban tal función, solteras, casadas o viudas. A veces se indica el nombre del marido, pero no sabemos si vivía o había fallecido, por ejemplo Astruga, "muller d'Abrafim Cofe». En el censo no se menciona ninguna profesión de los hebreos. Tampoco ninguno de los judíos mencionados en el mismo aparece documentado en otros lugares, aunque debemos recordar que la documentación real sobre judíos saguntinos en estos años está por estudiar, y faltan datos sobre documentación municipal o notarial. Los apellidos Legem, Barbut, Cofe, Toledano, Tauell, Lobell, etc. eran habituales en la aljama saguntina y también en otras del reino en este siglo.

Recordemos que los judíos estaban exentos del pago del morabatí y en el censo no se hace distinción entre los que, en teoría, deberían pagar y los que no, sino que simplemente recoge la lista de los judíos pecheros («juheus peyters»), los que pagaban el impuesto de la pecha. Lo que no sabemos es cuántos no la abonaban. De ahí que la presencia de judíos en estos censos sea una anomalía y que sólo aparezcan esporádicamente.

No han quedado más datos sobre demografia saguntina en el Trescientos. Lo único que sabemos es que la judería se salvó del asalto de 1391, aunque algunos hebreos del lugar se convirtieron al cristianismo; los años posteriores fueron difíciles para la comunidad, que se pudo recuperar gracias a las medidas favorables a los judíos dadas por Juan I: perdón general de cualquier delito a los moradores de la villa y protección para todos sus judíos; autorización para realizar testamentos $\mathrm{u}$ otros actos jurídicos ante el notario que quisieran; rebajas en las contribuciónes; autorización en 1394 para 
imponer sisas; suspensión de las investigaciones en posibles delitos sobre usura; etc.

Esta política proteccionista la mantuvieron los monarcas de la nueva dinastía Trastámara en la Corona de Aragón, y en 1418 Alfonso $\mathrm{V}$, a causa de la peste y la disminución de la población judía, permitió al maestre racional subvencionar a la aljama de Sagunto. Al mismo tiempo les dió un salvoconducto general para poder ir por todos sus reinos. Por entonces, 1421, la aljama judía de Sagunto tenía 60 fuegos (240 personas), según el morabatí de este año ${ }^{7}$, lo que supondría un aumento de población con relación a 1379 , sin que se pueda precisar más del censo judío por lo escueto de la propia noticia. Lo llamativo, sin embargo, es este crecimiento de la aljama, en contraste con el brusco descenso de la población cristiana, que de 1.156 fuegos en 1379 pasa a 592 en el año 1421, con un descenso de casi el $50 \%$ del total de habitantes.

Se ha atribuido este descenso de población en Sagunto, y también en comarcas vecinas como La Plana de Castellón, a la mortandad causada por las epidemias, generadas en buena parte por la insalubridad de los campos de arroz existentes en el término. No se puede negar la existencia de tales epidemias, tan frecuentes en los siglos bajomedievales, muchas de ellas de carácter local. Un testimonio de 1422 referido a los judíos de Sagunto es lo suficientemente elocuente al respecto. Ese año el maestre racional, por orden del monarca, para aliviar las cargas de la comunidad les perdona la mitad de la quinta parte de la suma que la aljama debe entregarle de las imposiciones internas de la misma. Era una medida que Alfonso $\mathrm{V}$ había dictado años atrás, el 6 de enero de 1418.

per tant com l'aljama dels dits juheus per rahó dels grans mortaldats que eren estades de poch temps ençà era estadadisminuida e entant opressa, que si per lo dit rey no y era provehit fora façilment desolada e despoblada ${ }^{8}$.

Por tanto, antes de comienzos de 1418, posiblemente el año anterior, Sagunto se vió afectado por una epidemia que puso en

7 ARV., Varia, 517. Dato procedente del citado trabajo de J. Villalmanzo y J. AleIXANDRE, La población de Morvedre.

${ }^{8}$ ARV., Maestre Racional, 41, fol. 294v-295r, 28-5-1422 Valencia. J. HinojosA Montalvo, The Jews, pág. 502, doc. 322. 
grave trance a la aljama hebrea y debió de ocasionar un descenso demográfico. El problema radica en saber si los 60 fuegos de 1421 suponían una recuperación - aunque fuera ligera- con respecto a 1418, que es lo normal, o todavía se mantenía la debilidad demográfica. Problema que es insoluble por falta de cifras comparativas. Lo único evidente es el aumento de población con respecto a 1379 y que en 1423 todavía la aljama de Sagunto se hallaba sumida en un estado de pobreza tal que le impedía al maestre racional cobrar el quinto perteneciente al rey de los citados impuestos internos de la aljama 9 .

No sabemos cuánto tiempo duraron estas dificultades internas, pero en 1438 aún no se había salido del bache y se seguía aludiendo a "les mortaldats que en temps passat son stades en la dita vila" y también a "algunes adversitats de la dita aljama e los singulars de aquella", que había provocado una gran disminución de la población judía, razón por la cual no podían hacer frente a la pecha y otras cargas reales. Ello obligó a Joan Mercader, baile general del reino, a encargar a Jaume Munyoç, baile local de Sagunto, que hiciera una pesquisa y obligara a todos los judíos que vivían dispersos en aquellas localidades del reino donde no había judería, así como a los de Castellón, Vila-Real y otros, y les forzara a pagar junto con los de Sagunto en las citadas exacciones reales, ya que el monarca no estaba dispuesto a renunciar a su renta ${ }^{10}$.

Hay, por tanto, en los años veinte y treinta de este siglo una crisis económica en la aljama saguntina que se reflejará en la demografía, con una tendencia al descenso, visible en el censo del morabatí de 1445 , en que el número de fuegos judíos se eleva a 52 , ocho menos que en $1421^{\prime \prime}$.

Todos los censados son varones, salvo tres mujeres, la de Jacob Gabriel y las viudas de Toledano y de Jeffuda Arami. Tampoco se mencionan profesiones ni datos que permitan individualizar a estos

\footnotetext{
9 ARV., Maestre Racional, 43, fol. 62v. J. Hinojosa, The Jews, pág. 502, doc. 324. El texto alude a "llur gran pobrea".

10 ARV., Bailía, 1148, fol. 468r. J. HinojosA, The Jews, pág. 547, doc. 457, 22-111438 Valencia.

"ARV., Varia, 477. A. Chabret, a partir de las noticias del manuscrito del P. Morató recoge la noticia de que en el libro de la pecha de 1445 figuraban cincuenta judíos que satisfacian pecha, dos menos que en el censo del morabatí, que en otro libro perteneciente a 1460 , con el título Juheus per vehinal, ascendian a cincuenta y uno. A. Chabret, Sagunto, II, pág. 350, nota 1.
} 
hebreos. En este caso, sin embargo, la documentación más abundante o mejor conocida, ha permitido que a muchos de los judíos citados en el censo los haya podido documentar a lo largo de estos años participando en las más variadas actividades de la vida cotidiana o judiciales ${ }^{12}$. Por ejemplo, Jeffuda Arami y Mossé Gallego, que ese año son los adelantados de la aljama; o Gento Abenjamín, casado con Astruga, y que había fallecido en 1453. A título orientativo he colocado en el mencionado censo entre paréntesis los años más cercanos a la fecha del censo en que los he documentado.

Lo más interesante es comparar los censos de población cristiana y judía de Sagunto en 1379, 1421 y 1445, que ofrecen el siguiente cuadro:

1379

1421

1445

\begin{tabular}{lccc}
\hline cristianos & 1.297 fuegos & 878 & 768 \\
& $(5.188$ habitantes $)$ & $(3.512)$ & $(3.072)$ \\
judíos & 43 fuegos & 60 & 52 \\
& $(172$ habitantes $)$ & $(240)$ & $(208)$ \\
\% total población & 3,3 & 6,8 & 6,7 \\
\hline
\end{tabular}

Hay que destacar el moderado crecimiento de la aljama de Sagunto, que en sesenta y cinco años aumenta su población en un $12 \%$, aunque con una ligera pérdida en 1445 con relación a 1421 . No es mucho pero, a la postre, nos muestra una comunidad con tendencia al crecimiento.

En cambio - y esto es lo que más llama la atención - la población cristiana de Sagunto está en franco declive y en estos años ha perdido más de 2.000 habitantes, decadencia que se ha atribuido a las epidemias. Ahora bien ¿cómo se explica que, por el contrario, los judíos hayan visto aumentar su población, no sólo desde el punto de vista cuantitativo sino también en el cómputo global del municipio, pasando del el 3,3\% al 6,7\% del total? Está claro que

12 Puede verse mi obra The Jews, en particular la lista de todos los judíos de Sagunto que he localizado entre 1391 y 1492, además del índice y del apéndice documental, en el que aparecen todos estos judíos. 
también se vieron azotados por las epidemias, pero cabe preguntarse si en menor medida que los cristianos, o si disfrutaban de una mejor sanidad. Quizá, aunque la higiene debía de ser deficiente para unos y otros. A modo de hipótesis y junto a este factor externo causante de un descenso demográfico por mortalidad, habría que añadir otros factores intrínsecos, propios de la comunidad cristiana, como por ejemplo la economía local, de la que desconocemos todo por estos años, pero cuya mala marcha pudo ocasionar emigraciones de miembros de la comunidad cristiana hacia otras localidades, mientras que la economía de la aljama pudo sortear mejor estas dificultades.

Lo cierto es que la judería de Sagunto se consolida a mediados del Cuatrocientos como la primera del reino y se inicia un proceso de recuperación, que parte no sólo del propio crecimiento vegetativo de la aljama, sino que también vino impulsada desde el exterior, a través de la emigración de judíos desde otras aljamas cercanas, principalmente de La Plana castellonense. Abundan las quejas de los adelantados de la aljama de Burriana a los de Sagunto por el pago de las pechas de los hebreos que desde Burriana se marcharon a Sagunto sin liquidar sus deudas fiscales. Recordemos que entre todas estas aljamas hubo siempre fuertes lazos familiares y la movilidad de sus miembros fue constante a lo largo de estos siglos. Bastaba que las circunstancias se tornaran más difíciles para los hebreos -como sucedió en Burriana o Vila-Real- para que marcharan a otra aljama en busca de mejores oportunidades.

Hay un testimonio definitivo de este crecimiento de la judería de Sagunto fechado el 10 de enero de 1476, cuando el baile general del reino ordenó a los adelantados de la aljama que se pusieran de acuerdo con el justicia y jurados de la villa para pagar la tacha, ya que "la dita juheria era augmentada", por lo que debía pagar más que en tiempos pasados ${ }^{13}$.

Las noticias que nos han llegado de finales de la centuria son tajantes al reconocer este crecimiento demográfico de la judería saguntina. Un documento del 3 de septiembre de 1493 - un año después de la expulsión- dirigido por el baile general del reino al rey Fernando II señala que en Sagunto «havia una gran població de juheus fins en nombre de cent cases e més»y cómo la marcha de los

${ }^{13}$ ARV., Bailia, 1155, fol. 567r. J. HinojosA, The Jews, pág. 68, doc. 755. 
judíos había dejado deshabitada no sólo la judería sino que la propia villa "resta despoblada e despoblada de pobladors». El objetivo de la autoridad real no era otro que el de atraer nuevos pobladores, en particular pelaires, que desarrollaran una industria textil local, contando con los privilegios y la posibilidad de constituirse en una cofradía, al igual que aquéllos tenían en Valencia ${ }^{14}$. Al margen de posibles exageraciones del funcionario de la Corona con el fin de atraerse la voluntad real, no cabe duda de las gravísimas repercusiones demográficas y económicas que la expulsión tuvo para el conjunto de la población saguntina.

Por las cantidades abonadas al fisco real para su embarque sabemos que el número de judíos saguntinos que marcharon hacia el exilio fue de setecientos is, lo que representaría un tercio de la población de la villa, que Chabret evaluaba en 500 casas, unas 2.000 personas aplicando un coeficiente 4. Eran, sin duda, el principal contingente hebreo del reino de Valencia. Su destino final fue Pisa o Nápoles. Se cerraba así un capítulo de la historia judía valenciana y de la demografía de Sagunto, con un balance negativo para ambas.

Pecha de 137916

$\begin{array}{ll}\text { Astrug Hiçan } & \text { Alio Far } \\ \text { Abrafim Legem } & \text { Jucef Axi } \\ \text { Jucef Ceruch } & \text { Jafuda Adzaron } \\ \text { Jacob Barbut } & \text { Per los hereus de Jafuda } \\ \text { Astruch Jucef } & \text { Cofe, fill de Benvenist Cofe. } \\ \text { Abrafim Cofe } & \text { Fario Cofe } \\ \text { Jacob Abendara } & \text { La muller de Jucef Lobell } \\ \text { Abram Malaqui } & \text { Jafuda Legem } \\ \text { Içach Tello } & \text { Abrafim Asio } \\ \text { Daviu el Rau } & \text { Icach Axi } \\ \text { Icach Tauell } & \text { Mose Pasarell } \\ \text { Azmet Toledano } & \text { Goig, muller que fon de Caydia Malaqui } \\ \text { Icach Bonet } & \text { Isach Aseyo, fill de Regina }\end{array}$

${ }^{14}$ ARV., Real, 596, fol. 133 bis r-134r. J. HinojosA, The Jews, pág. 68, doc. 879.

is Esta cifra concuerda con la que da L. PILEs Ros al referirse a las consecuencias de la expulsión en su trabajo "La expulsión de los judíos en Valencia". Sefarad XV (1955) 89-102, 100, donde señala que los judíos tenían ciento veinte casas que en conjunto estaban habitadas por más de seiscientas personas, según informes de las cuentas del Maestre Racional.

${ }^{16}$ ARV., Maestre Racional, 9826, fol. 104r-106r. 
Astruch Malaqui

Daviu Maymado

Astruxa, muller d'Abrafim Cofe

Icach Balester

Maymó Bubo

Salamó Malequí

Estella, muller que fon de

Jafuda Adzaron

Jacob Lexem

Pecha de $1445^{17}$

En la juheria de la dita vila

Son franchs per privilegi

N'Astruch Çaporta (1457)

Salamó Fonduix (1436)

La viuda de Jeffuda Arami

Ycach Bonet (1448)

Salamó Tarfón (1433)

Jeffuda Molina

Samuel Cap $(1434,1464)$

Salamó Aroti (1469)

Maymó Adzaro (1455)

Jucef Gallego (1452)

Abraham Xamblell (1447)

Mossé Azoffi

Abraham Azoni e son fill (1447)

Mossé Gallego, menor (1445)

Mossé Zaruch (1442)

Samuel Abdet

Abraham, fill de Mordofay

Prefet Crespí (1449)

Samuel Quatorze (1431)

Gento Ardit (1430)

Saçón Arroti

Samuel Ardurell (1457)

Ycach, fill de Menahem

Cahadia Cabalmale

La viuda de Toledano apellada Oro

La muller que era de Jacob Gabriel
Meora Acara

Salamó Aseyo

Xeremies Cofe

Caçon Azamel

Jucef Axauarquí

Jacob Porporer

Haym Asio

Faro Alolayx
Faym Bariellxy

Samuel Bonet $(1435,1455)$

Gento Abenjamín (1445)

Ycach Facan (1440)

Aym Vinaig (1430, 1460)

Ycach Tarfón

Salamó Abencalema

Abraffim Rodrich

Abrafim Legem (1448)

Mossé Gallego, menor (1445)

Salamó Xamblell (1447)

Astruch Malaquí (1422)

Salamó Aztori (1451)

Jucef Aztori (1461)

Abrafim Zotlem

Jacob Barbut (1438)

Abraham Agi

Samuel Agi (1452)

Mossé Boffor

Natan Lobell (1430)

Jacob Rodrich

Samuel Arami

Jucef Cerfati (1462)

Abrahim Cohen

Faraig de Luna

17 ARV., Varia, libro 517, Varia, 477. 


\section{RESUMEN}

Una de las principales dificultades con las que se enfrentan los que estudian el judaísmo valenciano es conocer la demografía de las aljamas. Nuestro objetivo es dar unos breves apuntes sobre la población de la judería de Sagunto, la segunda en importancia del reino de Valencia, a partir de las listas conservadas del impuesto del morabatí, de 1379 y 1445, completadas con otras noticias dispersas. Frente a un despegue demográfico del siglo XIII y principios del XIV, contrasta la crisis que se produjo a raíz de la peste de 1348 y, sobre todo, de la guerra con Castilla, la de los dos Pedros. La judería se salvó de las violencias de 1391 y en el siglo XV su población siguió creciendo con relación a 1379, en contraste con el descenso de casi un $50 \%$ de la población cristiana de la villa. En 1492, con motivo de la expulsión, partieron hacia el exilio setecientos judíos saguntinos.

\section{SUMMARY}

One of the main difficulties found by the scholars of Valencian Judaism is to define the demographics of the Jewish quarters. Our purpose in this paper is to provide a few notices on the Jewish population of Sagunto - the second most important enclave in the kingdom of Valencia - from the two "morabatí taxation lists that have been preserved, corresponding to the years 1379 and 1445 , and also from other scattered information about the 14th and 15th centuries. In contrast with the demographic boom of the 13th century, we find the crisis caused by the plague in 1348 and the war against Castilla, known as the war of "los dos Pedros». The Jewish quarter was not affected by the violence of 1391 and, in the 15th century, the Jewish population continued growing if compared to the population of 1379 -a remarkable contrast with the almost $50 \%$ decrease of the Christian population in that community. In 1492, as a result of the expulsion, seven hundred Jews from Sagunto were sent into exile. 